\title{
Assimilating phenology datasets automatically across ICOS ecosystem stations
}

\author{
Koen Hufkens ${ }^{1 *}$, Gianluca Filippa ${ }^{2}$, Edoardo Cremonese ${ }^{2}$, Mirco Migliavacca $^{3}$, Petra D'Odorico ${ }^{4}$, \\ Matthias Peichl ${ }^{5}$, Bert Gielen ${ }^{6}$, Lukas Hörtnagl ${ }^{7}$, Kamel Soudani $^{8}$, Dario Papale ${ }^{9}$, Corinna Rebmann ${ }^{10}$, \\ Tim Brown ${ }^{11}$, and Lisa Wingate ${ }^{1}$
}

${ }^{1}$ UMR 1391 ISPA, INRA, 71 avenue Edouard Bourlaux, 33140, Villenave D’Ornon, France

${ }^{2}$ Climate Change Unit, Environmental Protection Agency of Aosta Valley, 44 Loc. Grande Charriere, 11020, St. Christophe, Italy

${ }^{3}$ Max Planck Institute for Biogeochemistry, Hans Knöll Straße 10, D-07745, Jena, Germany

${ }^{4}$ Department of Biology, University of Toronto, 3359 Mississauga Road, ON L5L 1C6, Mississauga, Canada

${ }^{5}$ Department of Forest Ecology and Management, Swedish University of Agricultural Sciences, Skogsmarksgränd 1, 90183 Umeå, Sweden

${ }^{6}$ Department of Biology, University of Antwerp, Universiteitsplein 1, 2610, Wilrijk, Belgium

${ }^{7}$ Institute of Agricultural Sciences, ETH Zurich, Universitätstrasse 2, 8092, Zurich, Switzerland

${ }^{8}$ Ecology Systematics and Evolution Laboratory, University Paris Sud, 91405, Orsay, France

${ }^{9}$ Department of Forest Science and Environment, University of Tuscia, Via Santa Maria in Gradi 4, 01100, Viterbo, Italy

${ }^{10}$ Department of Computational Hydrosystems, Helmholz Centre for Environmental Research, Permoserstraße 15, 04318, Leipzig, Germany

${ }^{11}$ Research School of Biology, Australian National University, ACT 2601, Acton, Australia

Received June 29, 2018; accepted June 29, 2018

\begin{abstract}
The presence or absence of leaves within plant canopies exert a strong influence on the carbon, water and energy balance of ecosystems. Identifying key changes in the timing of leaf elongation and senescence during the year can help to understand the sensitivity of different plant functional types to changes in temperature. When recorded over many years these data can provide information on the response of ecosystems to long-term changes in climate. The installation of digital cameras that take images at regular intervals of plant canopies across the Integrated Carbon Observation System ecosystem stations will provide a reliable and important record of variations in canopy state, colour and the timing of key phenological events. Here, we detail the procedure for the implementation of cameras on Integrated Carbon Observation System flux towers and how these images will help us understand the impact of leaf phenology and ecosystem function, distinguish changes in canopy structure from leaf physiology and at larger scales will assist in the validation of (future) remote sensing products. These data will help us improve the representation of phenological responses to climatic variability across Integrated Carbon Observation System stations and the terrestrial biosphere through the improvement of model algorithms and the provision of validation datasets.
\end{abstract}

*Corresponding author e-mail: koen.hufkens@gmail.com
Keywords: ICOS, near-surface remote sensing, proximal sensing, digital repeat photography, phenology, protocol

\section{INTRODUCTION}

Phenology is the study of the timing of recurrent biological events, the causes of the timing with regard to biotic and abiotic forces, and the interrelations among phases of the same or different species (Leith, 1974). Plant phenological events such as leaf out, flowering and leaf senescence are driven by photoperiod, year to year variations in temperature and moisture availability (Delpierre et al., 2016; Xie et al., 2015) and are "perhaps the simplest process in which to track changes in the ecology of species in response to climate change" (Rosenzweig et al., 2007). These subtle variations in phenology can impact directly the length of the growing season and more importantly, the seasonality of carbon, water and energy exchanges between terrestrial ecosystems and the atmosphere (Baldocchi et al., 2005; Richardson et al., 2013). Recent studies have shown

(C) 2018 Institute of Agrophysics, Polish Academy of Sciences 
that it is currently uncertain how longer growing seasons will affect the carbon sequestration of ecosystems (Keenan et al., 2014; Piao et al., 2008; Wohlfahrt et al., 2013). In addition, the exact timing of plant development stages and their response to climate, environmental conditions, and management practices are still poorly represented in land surface models (Richardson et al., 2011; Sus et al., 2010). Thus, monitoring the seasonal and inter-annual variability of canopy phenology across a pan-European research infrastructure such as the Integrated Carbon Observation System (ICOS) ecosystem stations will help us better understand the role of climate change in regulating the carbon uptake period of ecosystems across Europe.

Visual observations of phenology, made in situ by human observers, are laborious and prone to observer bias (Morrison and Young, 2016), furthermore they cannot be easily scaled up to the ecosystem level. There is therefore a need to supplement long-term visual observations with automated techniques such as those provided by digital repeat photography (hereafter referred to as phenocams) at high temporal and spatial resolution. In this context, Kosmala et al. (2016) showed that visually estimated dates for key phenological events agree well with phenocam green chromatic coordinate (Gcc) time series derived phenology metrics. Yet, not all phenocam metrics can be easily linked to classical phenology metrics from field observations (e.g. bud-burst, flowering, leaf expansion, etc, e.g. Browning et al., 2017; Liang et al., 2011, Wingate et al., 2015). Similarly, although phenocams are increasingly being used to study conservation and restoration ecology. In particular they are being used to document disturbances such as deforestation, fire events, insect outbreaks, flooding and vegetation recovery (Alberton et al., 2017). However, visual observations still play a key role in describing certain details not easily quantified automatically by current phenocam indices during these events. Thus, more work is required to characterise better the information carried by phenocam data within this context.

Phenocams are most widely used to monitor the development of land surface conditions such as greenness and broad band Normalized Vegetation Index (NDVI) that can be calculated from high-frequency (i.e., multiple images per day) phenocam imagery (Filippa et al., 2018). Metrics extracted from these time series (i.e. beginning and end of the growing seasons, growing season length, and so forth) provide a valuable tool for linking and validating satellite products and field observations. Moreover, phenological metrics extracted from phenocams have recently been used to refine phenological models in a variety of ecosystems and might provide insights into vegetation responses to climatic extremes (Chen et al., 2016; Cremonese et al., 2017; Melaas et al., 2016), and complex biosphere-atmosphere feedbacks (Green et al., 2017).
The use of images from phenocams has the advantage that the temporal resolution of measurements can be increased, and the footprint of the field observations can be broadened in an effort to maintain consistency with eddy covariance and satellite observations, whilst beneficially reducing the costs of field-based observations (e.g. Sonnentag et al., 2012). Phenocams have been demonstrated useful to capture land surface phenology (Hufkens et al., 2012; Klosterman et al., 2014) and also seasonality in gross primary production (GPP) estimated from eddy covariance measurements for a variety of plant functional types (Browning et al., 2017; Migliavacca et al., 2011; Moore et al., 2017; Toomey et al., 2015; Wingate et al., 2015). Phenocam-derived NDVI time series also exhibit good agreement when compared to both remote sensing and broadband spectral measurements. In addition, these different phenocam derived metrics provide complimentary information that reflect structural development of a canopy and biomass in addition to leaf colouration, which domiates the Gcc index (Filippa et al., 2018) and supports modelling studies at the canopy scale (Wingate et al., 2015).

Several phenology monitoring programs that use automated digital photography already exist in the USA (US PhenoCam Network), Europe (EuroPhen), Japan (Phenological Eyes Network) and Australia (TERN Australian Phenocam Network). The guidelines presented here have been developed for ICOS ecosystem stations in collaboration with the European Phenology Camera Network (EuroPhen), a collaborative initiative setup to promote the recording of phenological events alongside detailed micrometeorological observations (Wingate et al., 2015) and in a manner that will facilitate a smooth integration within the large-scale digital camera repository hosted by NASA ORNL DAAC (Richardson et al., 2018a).

The overall goal of the ICOS automated phenology monitoring is to determine the trends in the seasonal patterns and interannual variability in phenology of key European species in order to assist the carbon and water cycle research community in detecting and understanding the effects of climate change on ecosystem function. We envision that the specific monitoring objectives would encompass a harmonised network of digital cameras to ensure consistent observations across sites and ecosystems. This would ensure standardised data collection to enable routine processing for the extraction of vegetation colour indices and phenophase dates from the cameras (such as budburst and leaf fall dates). These data would also provide continuous trajectories of canopy dynamics that could be linked to co-located ecosystem properties, carbon, water and energy fluxes, biotic and abiotic hazards (such as pathogens and pests, drought, storm), and land management practices. The long-term commitment of ICOS also allows for the detection of long-term trends and interannual variability in the timing and duration of key phenophases (such as onset of the green-up, peak of the greenness, green off- 
set) that have a strong impact on the exchange of carbon, water and energy with the atmosphere, and provide a visual historical record of landscape and environmental change at ICOS ecosystem stations.

Phenocam data would also allow ICOS to explore in more detail relationships between phenological events, climatic variables and soil moisture states in order to develop hypotheses about the impacts of climate change on phenology, ecosystem carbon uptake and water losses. Moreover, the ICOS framework can help ensure a standardised dataset that can serve as both a calibration and validation dataset for remote sensing data or products and various modelling efforts. In addition, the intuitive nature of the phenocam imagery and subsequent processing allows for easy outreach and integration in education programs across Europe. Here, we provide a practical guideline on how to install phenocams at stations within and beyond ICOS to ensure optimal quality in the acquired images within the context of the ICOS network. Additionally, we also provide guidelines on how to extract and process color indices time series and extract phenophase dates.

\section{METHODOLOGY}

\section{Measurement methods and instrumentation}

Within Europe there are many digital camera types, that can be networked and automated to some extent, operating at long-term flux stations. The dominant digital camera used within the ICOS network, to date, remains the Stardot Netcam SC5 (Stardot Technologies, Buena Park, CA). This camera is used extensively by the PhenoCam network, coordinated by Andrew Richardson (Richardson et al., 2018a) and the US National Ecological Observatory Network (NEON, SanClements and Roberti, 2016). Experience over the past few years has demonstrated that the StarDot camera is simple to use and install in the field. It is reliable under the environmental conditions experienced at most flux sites (Richardson et al., 2018a,b) and benefits from good technical support from the company. Moreover, the Stardot Netcam SC5 IR provides the possibility of recording sequential RGB and monochrome RGB + NIR images, this dual capability is not found in any other networked camera. This opens up the possibility of obtaining an additional camera-based proxy of NDVI (Filippa et al., 2018; Petach et al., 2014). As such, we prefer the Stardot Netcam SC5 IR camera within the context of establishing a standardized network of cameras.

\section{Instrumental setup}

A number of general recommendations can be made on how to install a phenocam. If possible, the camera should be facing away from the sun's direction at solar noon (12:00 local solar time or true North in case of the ICOS) to minimise lens flare and maximise illumination of the canopy. If it is not possible to point the camera away from the sun's direction at solar noon, the camera can be alternatively pointed East ( $90^{\circ}$ from true North) with an acquisition time centered on 15:00 local solar time or West $\left(270^{\circ}\right.$ from true North) with an acquisition time centered on 10:00 local solar time. However, pointing the camera toward the sun's direction at solar noon must be avoided even if this is where the dominant flux footprint is located since images contaminated by direct sunlight cannot be used.

Similarly, the camera field of view must be maximised for information content and image quality. Therefore, the portion of sky included in the image should not exceed $1 / 5$ $(20 \%)$ of the image (Fig. 1). For sites with a short canopy and without a prevailing wind direction it could be an option to mount the camera on a separate pole $c a .50 \mathrm{~m}$ away from the flux tower in order to view all sectors around the flux tower and maximise the portion of the climatological footprint area sampled with the camera. This would be especially advantageous in heterogeneous landscapes such as peatlands and managed grasslands and could provide a better representation of the footprint in such ecosystems.

When installed on a tower, the camera should be securely mounted, and if possible, about 10-20 m from the foreground portion of the canopy. When installed on tripods or masts (e.g. low canopies like grassland, cropland, shrubland, etc.) the camera should be mounted at a minimum distance of $2 \mathrm{~m}$ from the foreground portion of the canopy. The combination of the camera height above the canopy and the viewing angle can affect the vegetation colour indices, by including more or less soil background in the regions of interest. As future research will compare vegetation colour indices between sites, it is desirable to minimise the extent of soil surface observed in the image. In the case of fast growing canopies (e.g. cropland, short rotation coppice), future plant growth needs to be considered by allowing enough space within the field of view to capture canopy growth and to avoid changing the position of the camera during the growing season. Also, if the camera is installed in the proximity of trees it is necessary to ensure that new growth of branches does not obscure the view during the growing season with regular pruning.

We also recommend installing a below canopy camera in forest sites to track understory phenology, especially at those sites where the above canopy camera can not be used (e.g. dense canopies) for this purpose (Bater et al., 2011). The below canopy camera must be installed following the same recommendations provided for the above canopy camera. Above and below canopy cameras must have the same orientation (ideally pointing North to minimise directional effects caused by sun illumination angle). The camera should be mounted at approximately $3 \mathrm{~m}$ above the ground (or above the understory canopy). No main branches from the dominant trees should obstruct the field of view. Understory and above canopy cameras can also be used to measure the presence and depth of snow (Dickerson-Lange et al., 2015). 
a

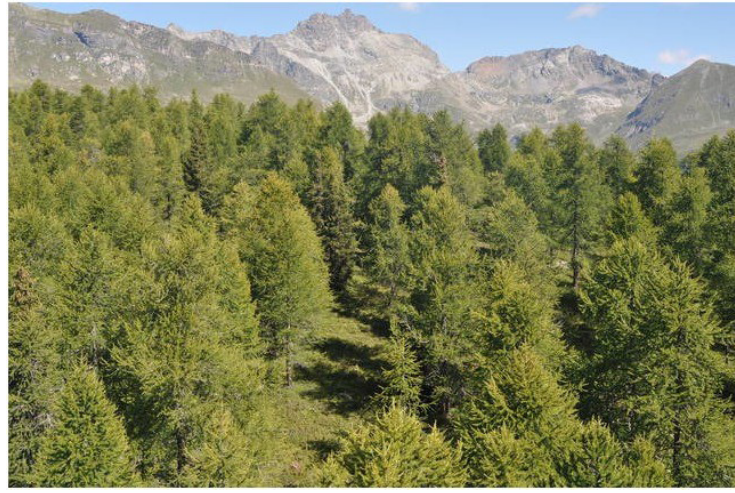

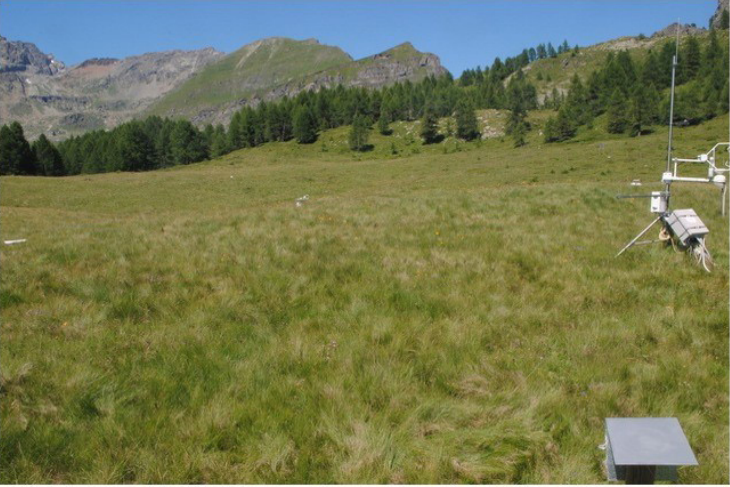
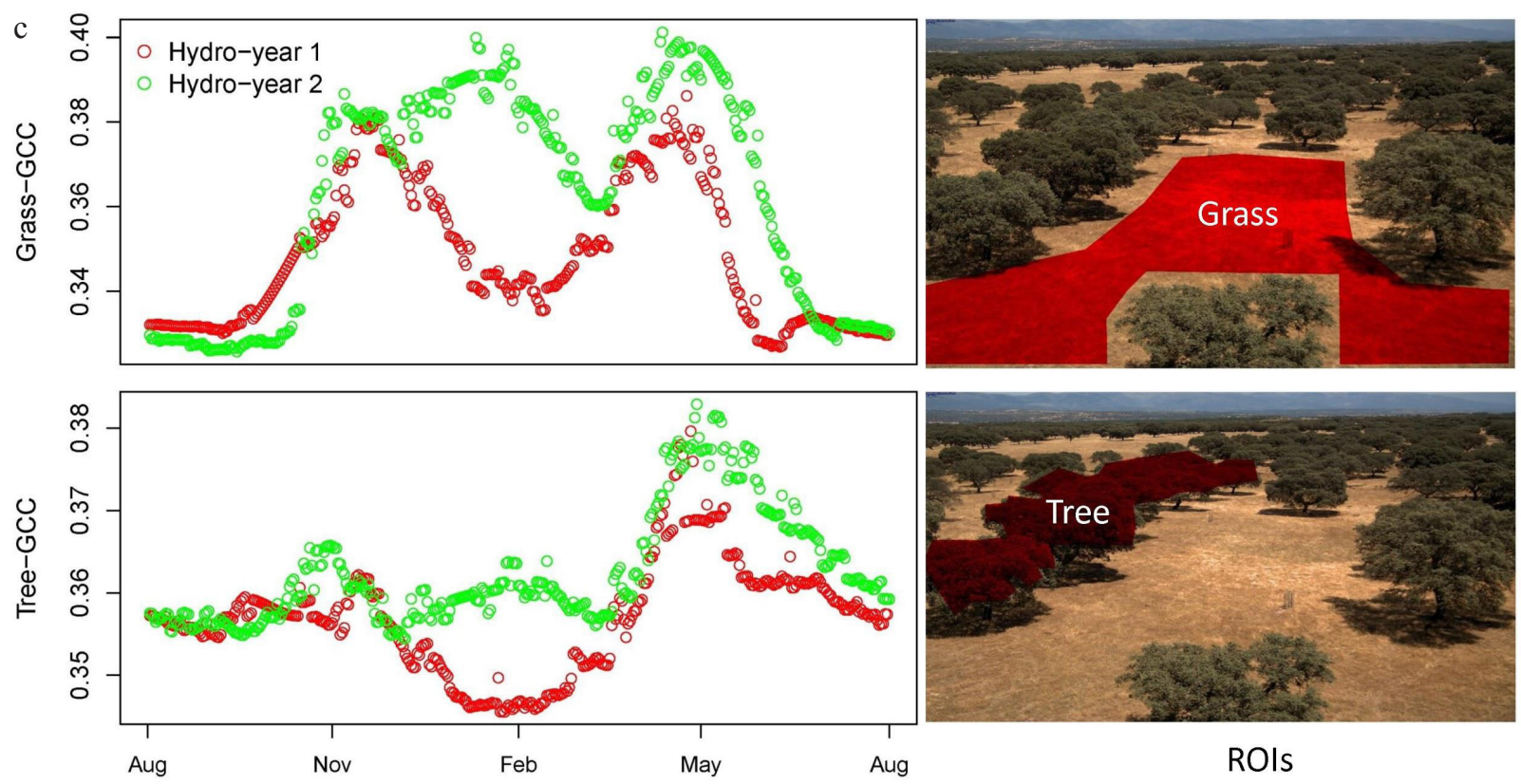

Fig. 1. Examples of camera field of view in a forest: $\mathrm{a}$ - and grassland site $\mathrm{b}$ and, $\mathrm{c}$ - examples of the ROI selections for the Majadas de Tietar (FLUXNET ID ES-Lm2) site capturing both the understory grasses (top panel) and the Holm Oak canopy (bottom panel). Red dots represent the data collected during the hydrological year 1 (August 1st, 2014 to July 31st, 2015); green dots represent the data collected during the hydrological year 2 (August 1st, 2015 to July 31st, 2016). The region of interest (ROI) used to compute the green chromatic coordinates (GCC) are depicted in red in the images (right panels).

To ensure standardized configuration the Stardot Netcam SCF IR should not be manually configured, instead the configuration of this camera should be executed by using a dedicated installation script (i.e. PhenoCam Installation Tool, or PIT; https://khufkens.github.io/phenocam-installation-tool/). The PIT ensures that the settings of the Stardot Netcam SC5 IR camera adhere to the recommended ICOS settings. In particular, the exposure mode is set to a fixed white balance (in order to minimise in-camera processing of day-to-day changes in illumination and RGB ratios), the date and time settings (set to local standard time when provided an UTC offset during installation), the file format and compression ratio (jpeg - high quality), standardized imprinting of date, time, exposure settings or camera ID on the image as well as a standardised file name convention are all configured by the PIT. Although data is stored in the jpeg format data quality loss is minimal. Previous research has shown that JPEG compression ratios only negatively influence the retrieved colour indices at very high compression rates $(>90 \%$, Sonnentag et al., 2012). The filename convention used is particularly important as it underpins all subsequent post-processing. As such, site names must not contain:

1. underscores in the site name (dashes and numbers are possible),

2. windows or linux illegal characters such as a forward or backward slash (/), or periods.

The final format is defined as: sitename_YYYY_MM DD_HHMMSS.jpg and supports the Fluxnet site naming conventions (e.g., BE-Bra: BE-Bra_2014_06_05_123000. jpg). For a more detailed outline of the instrumentation and installation of a Stardot Netcam SC5 IR camera we refer to the ICOS instructions document. 


\section{Spatial and temporal sampling design}

After configuration, a Stardot Netcam SC5 IR camera will transmit data automatically to the ICOS Ecosystem Thematic Center (ETC) File Transfer Protocol (FTP) server, or a local FTP server if a site's network connection is unreliable. The data transmitted includes: an RGB and RGB + IR image and their corresponding meta-data (e.g. exposure) at a set time interval (e.g. 4:00 - 22:00 h). If the near-real time transfer of images from the phenocam to the ICOS ETC server is not possible, it is advised that the images are uploaded manually by the PI every two weeks. Deployment of the phenocams will happen throughout the ICOS network, reflecting the spatial coverage and representability in terms of plant functional types of the network.

\section{Calibration and maintenance}

Although a sensor intercomparison of the Stardot Netcam SC5 IR cameras has shown limited sensor deterioration over time, and hence stability in the retrieved data (Richardson et al., 2018a,b), changes in the field of view are a major source of variability in the retrieved image data. It is therefore advised that, the position of the camera mounting structure is chosen to avoid accidental bumps or movement when other co-located equipment is being serviced, the field of view is never changed during the active growing season. If a change in the field of view is necessary, then this should be completed at least two months before the spring foliage development. Upon replacing a camera, care must be taken to match the new field of view with the previous field of view as closely as possible. In general, report any change in the field of view to the network co-ordinator. Avoid the presence of fast growing leaves or portion of branches in the foremost portion of the image as seasonal coherence of the regions of interest (ROIs) can be compromised.

\section{Post-processing}

Processed output data will be available through the ICOS data portal which will rely on the python vegindex package (https://github.com/tmilliman/python-vegindex) as a backend to calculate Gcc time series, and the "phenocamr" R package front end for outlier detection, smoothing and the estimation of phenological transition dates (e.g. the start of the season; https://khufkens.github.io/phenocamr/). The vegindex package excludes images taken at a solar angle smaller than 10 degrees (dark images), ingests multiple ROIs and has the ability to quickly generate vegetation colour index time series. A detailed description of the algorithms for both the back and front-end processing are provided in Richardson et al. $(2018 \mathrm{a}, \mathrm{b})$ and Hufkens et al. (2018), respectively.

It is anticipated that in the near future an application programme interface (API) will be created to access processed data output. Nonetheless, if PIs wish to process their own digital images a number of algorithms are now freely available to generate time-series of vegetation colour indices. For example, the open source R package, Phenopix has been developed recently by Filippa et al. (2016) and can be downloaded freely from the R CRAN network. Phenopix is an easy-to-use R-package that provides a standardised processing algorithm for extracting vegetation colour indices (e.g. the Gcc amongst many) and phenological transition dates calculated or parameterised from a range of different extraction techniques (Fig. 2). Multiple ROIs are recommended for ecosystems with heterogeneous canopies (e.g. mixed forests, grazed grasslands or peatlands) in order to capture the phenology of multiple species (or plant functional types) or to capture understory phenology (Fig. 1c). To ensure consistency the same ROIs must be used throughout the season.

\section{Final dataset}

The processing of the image data using the vegindex and phenocamr packages will result in a set of standardised products. Data products provided will include, (colour) statistics for predefined ROI for each ICOS site, summarised data at 1 or 3 day intervals and estimates of phenological transition dates at three preset amplitude thresholds $(10,25$, $50 \%$ ). Data will be delivered in the form of rolling releases on an annual cycle.

\section{RESULTS AND DISCUSSION}

Digital repeat photography allow for the construction of a visual record of the changes in vegetation over time, that can then be summarised as time series of vegetation greenness. The documented linearity and stability of the sensor (Richardson et al., 2018a,b), the ability to record a camera derived NDVI (Filippa et al., 2018; Petach et al., 2014), the option to automate and standardise installation procedures, the excellent vendor support, and widespread adoption throughout other international networks (e.g. NEON, PhenoCam US) motivates the choice of the StarDot NetCam SC5 IR camera over other camera types at ICOS ecosystem stations. However, convenient data collection using StarDot NetCam SC5 IR cameras comes at the cost of an ever increasing demand for data storage, compounded by the requirement to protect data against loss through multiple backups, and an ever increasing burden of quality control. Although rarely acknowledged, dedicated data managers and software tools are key to successfully managing large network infrastructure.

Changes in canopy greenness can be quantified using a variety of colour indices such as the Gcc index, green excess indices (GEI), green red vegetation index (GRVI) or colour space transformation such as hue saturation value (HSV) colour space (Andresen et al., 2018; Nasahara and Nagai, 2015; Mizunuma et al., 2014; Richardson et al., 2009; Woebbecke et al., 1995). Time series of canopy greenness provide information about key processes of the 


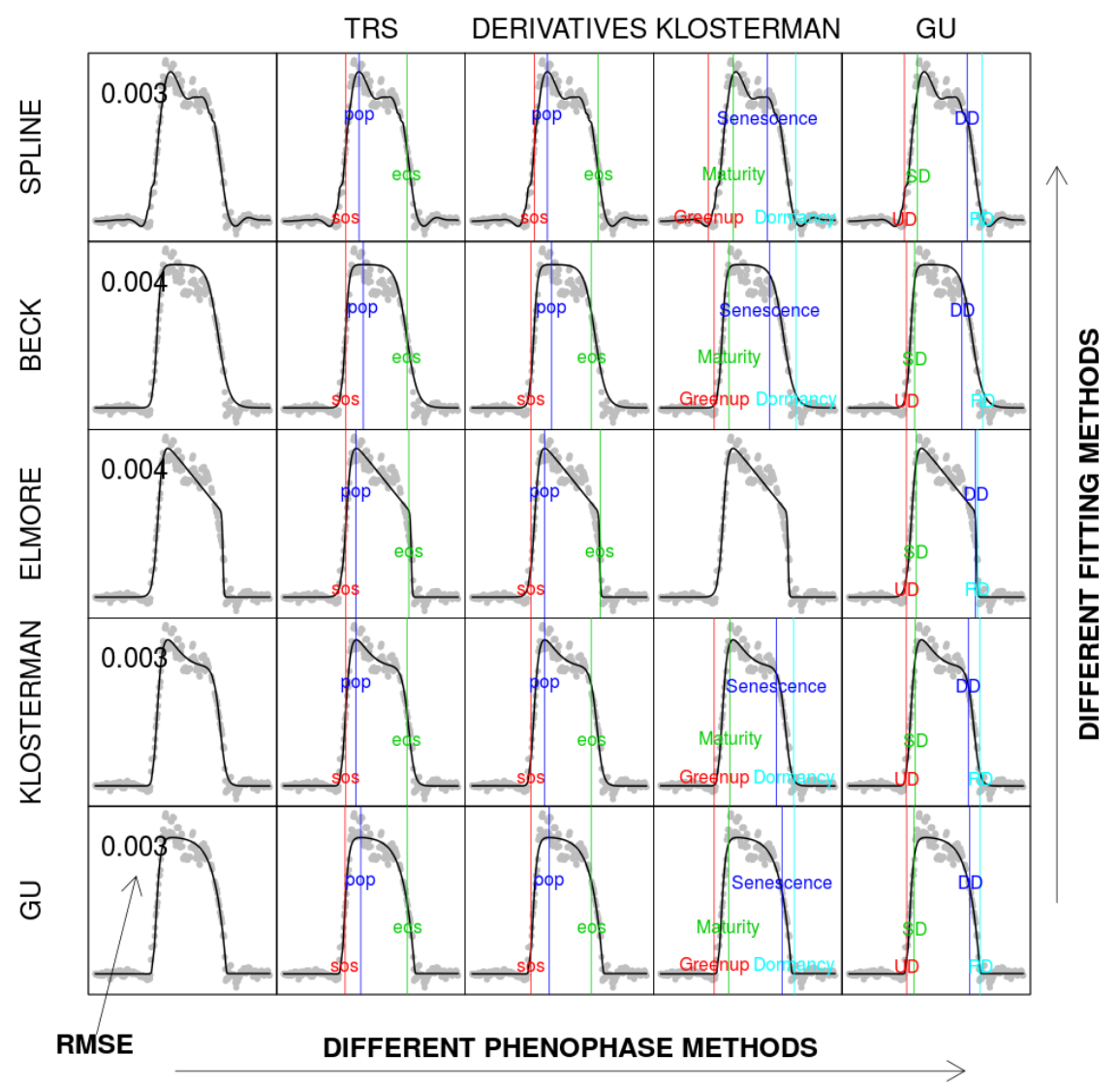

Fig. 2. Example of curve fitting outputs for a timeseries of gec at a deciduous broad-leaf forest (Bartlett Experimental Forest, year 2009). and important phenological events detected automatically with the Phenopix algorithms (Filippa et al., 2016). Plots in the same row share the same fitting method, whereas those in the same column share the same phenophase extraction method. The root mean square error (RMSE) for each fitting is also annotated in the first column. Abbreviations are as follows: sos: start of season, pop: period of peak, eos: end of season, UD: upturn date, SD: stabilization date, DD: downturn date, RD: recession date.

vegetation at the canopy level. In particular, using threshold or curve fitting techniques the approximate timing of leaf development and senescence can be estimated (Fig. 2). However, image based indices are not radiometric measurements and phenological metrics derived from digital cameras are related to temporal changes in canopy foliage or leaf pigment changes integrated across a larger ROI or on a pixel by pixel basis (Bowling et al., 2018; Snyder et al., 2016; Wingate et al., 2015). This lack of a radiometrically correct interpretation of the derived data poses challenges in the quality control of the data. For example, snow negatively affects data quality by introducing spuriously low Gcc values. Sun glare and improperly exposed images can cause similar aberrant colour index values, in particular when a camera is facing in the direction of the sun.

The described protocol ensures that the orientation of the camera will be favourable. Recent advances in both post-processing, using outlier detection (Hufkens et al., 2018; Richardson et al., 2018a,b) and Machine Learning (Kosmala et al., 2016) techniques, ensures automated quality control. Yet, some steps still require manual intervention and remain time intensive. For example defining
ROIs or detecting changes in the field of view can not be automatically defined. Ongoing development of new tools, such as the drawROI tool by Bijan Seyednarollah (https:/github.com/bnasr/drawROI) or Machine Learning techniques based on Convolutional Neural Networks (Hufkens, preliminary results; Fig. 3) will further facilitate the manual delination of ROI through easy workflows or near complete automation, respectivelly. However, even with consistent instrumentation and quality control the data retrieved remains effectively a unitless measurement and site inter-comparison in absolute Gcc values is often not possible. Normalizing Gcc values between 0 (baseline) and 1 (maximum) and constraining the maximum amplitude using external (climate) variables could be one solution to overcome this problem especially in moisture limited ecosystems (Hufkens et al., 2016). Both the instrumental setup dealing with the orientation and standardization of the field of view, and consistent and standardized processing limit sources of additional error in the final data products.

Other important information can be derived from the acquired images. Although, phenological events such as flowering and fruiting are difficult to detect, they can be 


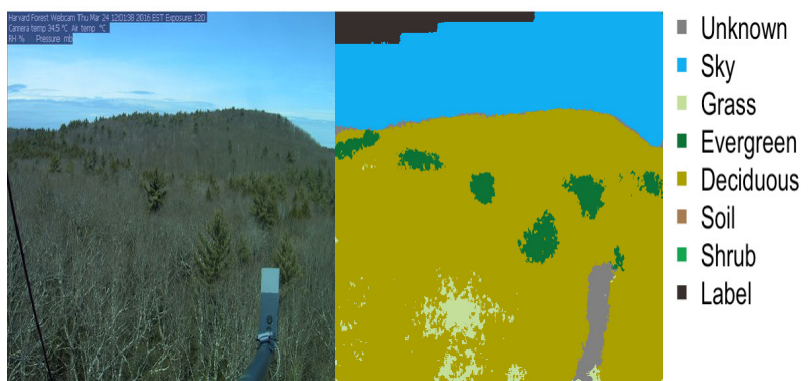

Fig. 3. A pixel level classification (left panel), with 8 different classes, of a single PhenoCam image at Harvard Forest (right panel) using a Convolutional Neural Network (CNN) classifier.

visually classified (Inoue et al., 2015; Nagai et al., 2011; Wingate et al., 2015) and can often explain changes in the seasonal patterns of the RGB time series (Inoue et al., 2015; Wingate et al., 2015). Similarly, phenocams can also be used for the detection of snow-cover or melt (Bernard et al., 2013; Dickerson-Lange et al., 2015; Ide and Oguma, 2013), and vegetation disturbances (Richardson et al., 2018b). For example, Dickerson-Lange et al. (2015) deployed phenocams beneath forest canopies exposed to different levels of management on the Pacific North-West Coast of America and could show that the duration of snow cover measured by phenocams varied consistently between replicated forest plots with different stand densities at different elevations and was consistent with step changes in co-located continuous soil temperature measurements. Such long-term information can be valuable for assimilating in models and help characterise better key ecohydrology and biogeochemical processes including the soil heat and evaporative fluxes as well as changes in the respiratory metabolism of belowground soil communities (Robroek et al., 2013). Such studies demonstrate the added-value of collecting both above-canopy and below-canopy images to connect variations in ecosystem energy and water balance to phenological change at ICOS sites over the coming decades.

The recent development of affordable cameras that can acquire information on both the RGB and NDVI signals may further improve our understanding of evergreen forest canopy phenology and physiology (Filippa et al., 2018; Petach et al., 2014). By computing the Gcc and NDVI with the same camera it is possible to tease apart important changes in the physiological and structural properties of the canopy that are both sensitive to changes in climate and important for understanding large-scale phenology patterns across the Mediterranean, temperate and boreal regions encompassed by the ICOS network of flux towers equipped with phenocams (Fig. 4). For example, Filippa et al. (2018)

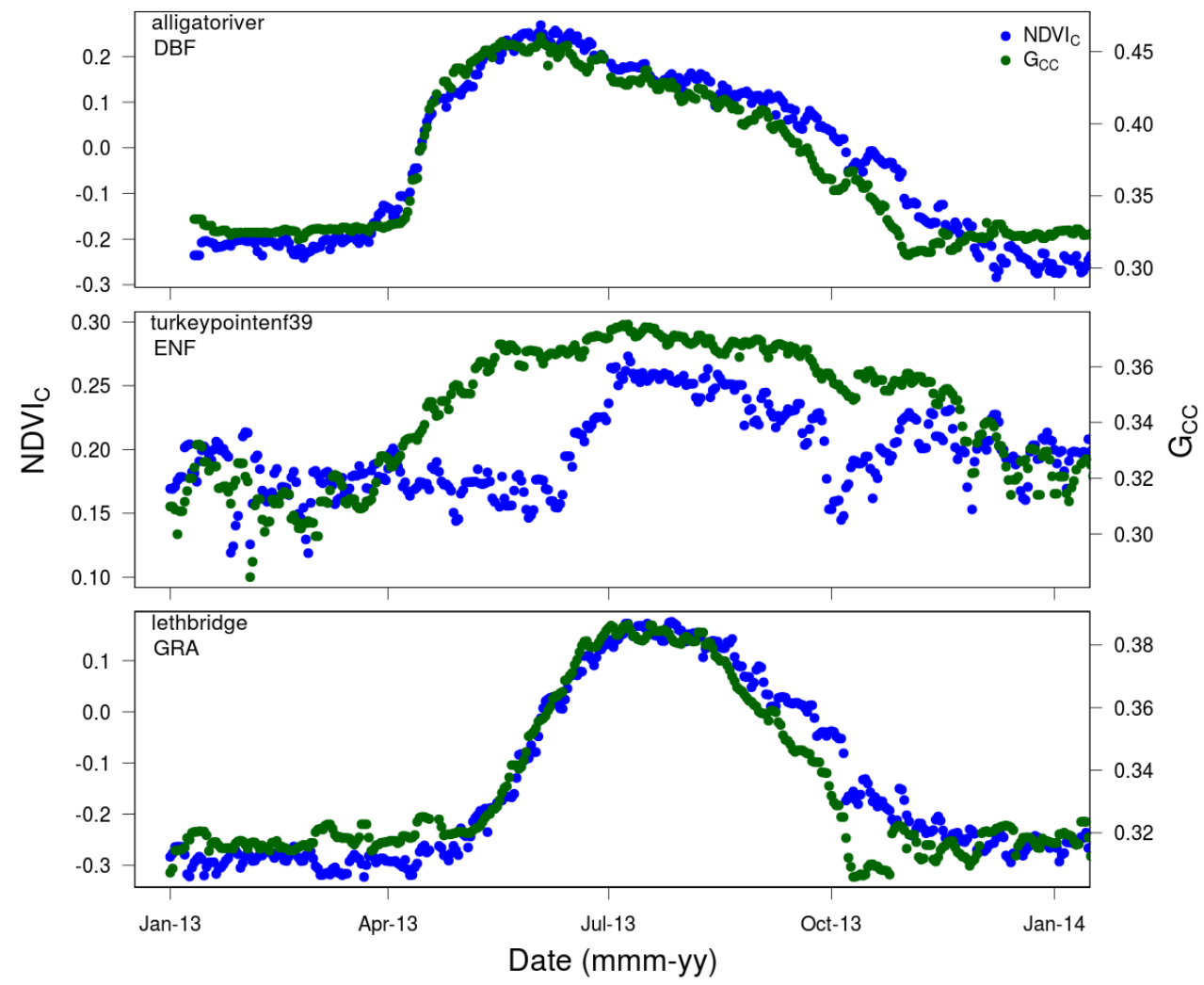

Fig. 4. Seasonal course of NDVI and GCC obtained from NIR-enabled Stardot Cameras from three different PhenoCam sites. DBF: deciduous broad-leaf forest; ENF: evergreen needle-leaf forest; GRA: grassland. 
has shown that both Gcc and NDVI values diverge due to differences in the timing of the change in leaf area index and leaf colour.

Although previous comparisons have been made between camera-derived and satellite-derived greenness indices (Hufkens et al., 2012; Klosterman et al., 2014; Liu et al., 2017; Ide et al., 2011) the deployment of new high spatial resolution platforms such as Sentinel-2 (https://sentinel. esa.int/) and WorldView3 (http://worldview3.digitalglobe. $\mathrm{com} /$ ) would merit additional efforts into the validation and upscaling of phenocam products (Vierling et al., 2018). Similarly, further comparisons between ecosystem fluxes (Richardson et al., 2010; Toomey et al., 2015), LAI or other vegetation structural changes (D'Odorico et al., 2015; Keenan et al., 2014; Wingate et al., 2015) gathered as part of the manual inventories (see this issue) would allow for a better understanding of the optical signals detected by cameras and increase their potential use in constraining ecosystem models (Chen et al., 2016; Hufkens et al., 2016; Melaas et al., 2016; Migliavacca et al., 2011).

Phenocams have been shown to provide a robust, simple and cost effective method to quantify the variability of canopy phenology that is consistent with eddy covariance flux measurements and satellite observations. At the same time, novel image processing techniques are gradually unlocking all information carried by phenocam data, expanding upon simple colour indices and providing insight in ecosystem disturbances, land surface dynamics, and classical phenological metrics such as flowering. The increasing availability of Machine Learning techniques might also prove to be an important tool in detecting classical phenology metrics from the information contained within individual phenocam images, and currently not easily detected using phenocam indices (e.g. Kosmala et al., 2016). Phenocams colocated with ICOS ecosystem stations therefore have a transformative potential, which through model evaluation, will help us better understand how climate change drives phenology, ecosystem disturbances as well as the carbon uptake period of ecosystems, including their biosphere-atmosphere interactions, across Europe. This ICOS repository when linked with the other growing open repositories of phenocam images such as the US PhenoCam (Richardson et al., 2018a,b) and the PEN network in Asia (Nagai et al., 2018) will provide a unique digital archive for Earth System scientists and profound visual evidence of the impact of climate change on natural ecosystems across the world in the forthcoming decades.

\section{CONCLUSIONS}

1. The installation of digital cameras that take daily images of plant canopies across the ICOS ecosystem stations will provide a reliable and important visual record of variations in canopy state and colour.
2. The standardisation of camera type and subsequent automation will facilitate the determination of consistent and reproducible canopy phenology products across different plant functional types across a coherent pan-European flux network.

3. This ground-based network will provide a link to new satellite products coming online with in-situ measurements of phenology and NDVI for calibration and inter-comparison purposes.

4. The final data products and installation instructions guarantee compatibility with other camera networks such as the National Ecological Observatory Network (NEON) and PhenoCam US, supporting large scale international collaborations.

\section{ACKNOWLEDGEMENTS}

This study has been carried out on the MicroMic project with financial support from the French National Research Agency (ANR) in the frame of the Investments for the future Programme, within the Cluster of Excellence COTE (ANR-10-LABX-45). We acknowledge all active members of the ICOS ecosystem working groups and all other people who contributed to the development of the ICOS ecosystem domain and the measurement protocols. We especially thank Daniella Franz for her encouragement and perseverance in bringing together all the ICOS protocols. The development of PhenoCam has been funded by the Northeastern States Research Cooperative, NSF's Macrosystems Biology program (awards EF-1065029 and EF-1702697), and DOE's Regional and Global Climate Modeling program (award DE-SC0016011). Images and data derived from PhenoCam imagery have been obtained from the PhenoCam network under the network's Fair Use data policy (https:// phenocam.sr.unh.edu/webcam/fairuse_statement/).MMacknowledge the Alexander von Humboldt Foundation for supporting this research with the Max-Planck Prize to Markus Reichstein at Majadas de Tietar, and Yunpeng Luo for contributing to the data analysis for Fig. 1c.

Conflict of interest: The Authors declare no conflict of interest.

\section{REFERENCES}

Alberton B., Torres R. da S., Cancian L.F., Borges B.D., Almeida J., Mariano G.C., Santos J. dos, and Morellato L.P.C., 2017. Introducing digital cameras to monitor plant phenology in the tropics: applications for conservation. Perspect. Ecol. Conserv., 15, 82-90. https:// doi.org/10.1016/j.pecon.2017.06.004 
Andresen C.G., Tweedie C.E., and Lougheed V.L., 2018. Climate and nutrient effects on Arctic wetland plant phenology observed from phenocams. Remote Sens. Environ., 205, 46-55. https://doi.org/10.1016/j.rse.2017.11.013

Baldocchi D.D., Black T.A., Curtis P.S., Falge E., Fuentes J.D., Granier A., Gu L., Knohl A., Pilegaard K., Schmid H.P., Valentini R., Wilson K., Wofsy S., Xu L., and Yamamoto S., 2005. Predicting the onset of net carbon uptake by deciduous forests with soil temperature and climate data: a synthesis of FLUXNET data. Int. J. Biometeorol., 49, 377-387. https://doi.org/10.1007/s00484005-0256-4

Bater C.W., Coops N.C., Wulder M.A., Hilker T., Nielsen S.E., McDermid G., and Stenhouse G.B., 2011. Using digital time-lapse cameras to monitor species-specific understorey and overstorey phenology in support of wildlife habitat assessment. Environ. Monit. Assess. 180, 1-13. https://doi. org/10.1007/s10661-010-1768-X

Bernard É., Friedt J.M., Tolle F., Griselin M., Martin G., Laffly D., and Marlin C., 2013. Monitoring seasonal snow dynamics using ground based high resolution photography (Austre Lovénbreen, Svalbard, $79^{\circ} \mathrm{N}$ ). ISPRS J. Photogramm. Remote Sens. 75, 92-100. https://doi.org/https:// doi.org/10.1016/j.isprsjprs.2012.11.001

Bowling D.R., Logan B.A., Hufkens K., Aubrecht D.M., Richardson A.D., Burns S.P., Blanken P.D., and Eiriksson D., 2018. Limitations to winter photosynthesis in a Rocky Mountain subalpine forest. Agric. For. Meteorol. 252, 241-255. https://doi.org/10.1016/j.agrformet.2018. 01.025

Browning D.M., Karl J.W., Morin D., Richardson A.D., and Tweedie C.E., 2017. Phenocams bridge the gap between field and satellite observations in an arid grassland ecosystem. Remote Sens, 9. https://doi.org/10.3390/rs9101071

Chen M., Melaas E.K., Gray J.M., Friedl M.A., and Richardson A.D., 2016. A new seasonal-deciduous spring phenology submodel in the Community Land Model 4.5: impacts on carbon and water cycling under future climate scenarios. Glob. Chang. Biol. 22, 3675-3688. https://doi. org/10.1111/gcb.13326

Cremonese E., Filippa G., Galvagno M., Siniscalco C., Oddi L., Morra di Cella U., and Migliavacca M., 2017. Heat wave hinders green wave: The impact of climate extreme on the phenology of a mountain grassland. Agric. For. Meteorol., 247, 320-330, https://doi.org/10.1016/j. agrformet.2017.08.016

D'Odorico P., Gonsamo A., Gough C.M., Bohrer G., Morison J., Wilkinson M., Hanson P.J., Gianelle D., Fuentes J.D., and Buchmann N., 2015. The match and mismatch between photosynthesis and land surface phenology of deciduous forests. Agric. For. Meteorol., 214-215, 25-38, https://doi.org/10.1016/j.agrformet.2015.07.005

Delpierre N., Vitasse Y., Chuine I., Guillemot J., Bazot S., Rutishauser T., and Rathgeber C.B.K., 2016. Temperate and boreal forest tree phenology: from organ-scale processes to terrestrial ecosystem models. Ann. For. Sci., 73, 5-25. https://doi.org/10.1007/s13595-015-0477-6

Dickerson-Lange S.E., Lutz J.A., Martin K.A., Raleigh M.S., Gersonde R., and Lundquist J.D., 2015. Evaluating observational methods to quantify snow duration under diverse forest canopies. Water Resour. Res., 51, 1203-1224, https://doi.org/10.1002/2015WR017618.Received

Filippa G., Cremonese E., Migliavacca M. et al., 2018. NDVI derived from near-infrared-enabled digital cameras: Applicability across different plant functional types. Agricultural and Forest Meteorology, 249, 275-285.

Filippa G., Cremonese E., Migliavacca M., Galvagno M., Forkel M., Wingate L., Tomelleri E., Morra di Cella U., and Richardson A.D., 2016. Phenopix: A R package for image-based vegetation phenology. Agric. For. Meteorol., 220, 141-150, https://doi.org/10.1016/j.agrformet.2016. 01.006

Filippa G., Cremonese E., Migliavacca M., Galvagno M., Sonnentag O., Humphreys E., Hufkens K., Ryu Y., Verfaillie J., Morra di Cella U., and Richardson A.D., 2018. NDVI derived from near-infrared-enabled digital cameras: Applicability across different plant functional types. Agric. For. Meteorol., https://doi.org/10.1016/j. agrformet.2017.11.003

Green J.K., Konings A.G., Alemohammad S.H., Berry J., Entekhabi D., Kolassa J., Lee J.E., and Gentine P., 2017. Regionally strong feedbacks between the atmosphere and terrestrial biosphere. Nat. Geosci., 10, 410-414. https://doi. org/10.1038/ngeo2957

Hufkens K., Basler D., Milliman T., Melaas E.K., and Richardson A.D., 2018. An integrated phenology modelling framework in R. Methods Ecol. Evol. 9, 1-10. https:// doi.org/10.1111/2041-210X.12970

Hufkens K., Friedl M., Sonnentag O., Braswell B.H., Milliman T., and Richardson A.D., 2012. Linking nearsurface and satellite remote sensing measurements of deciduous broadleaf forest phenology. Remote Sens. Environ., 117, 307-321. https://doi.org/10.1016/j.rse.2011.10.006

Hufkens K., Keenan T.F., Flanagan L.B., Scott R.L., Bernacchi C.J., Joo E., Brunsell N.A., Verfaillie J., and Richardson A.D., 2016. Productivity of North American grasslands is increased under future climate scenarios despite rising aridity. Nat. Clim. Chang., https://doi. org/10.1038/nclimate2942

Ide R., Nakaji T., Motohka T., and Oguma H., 2011. Advantages of visible-band spectral remote sensing at both satellite and near-surface scales for monitoring the seasonal dynamics of GPP in a Japanese larch forest. J. Agric. Meteorology, 67, 75-84.

Ide R. and Oguma H., 2013. A cost-effective monitoring method using digital time-lapse cameras for detecting temporal and spatial variations of snowmelt and vegetation phenology in alpine ecosystems. Ecol. Inform., 16, 25-34. https://doi.org/ https://doi.org/10.1016/j.ecoinf.2013.04.003

Inoue T., Nagai S., Kobayashi H., and Koizumi H., 2015. Utilization of ground-based digital photography for the evaluation of seasonal changes in the aboveground green biomass and foliage phenology in a grassland ecosystem. Ecol. Inform., 25, 1-9, https://doi.org/10.1016/j.ecoinf. 2014.09.013

Keenan T.F., Gray J., Friedl M.A., Toomey M., Bohrer G., Hollinger D.Y., Munger J.W., Keefe J.O., Schmid H.P., Wing I.S., Yang B., and Richardson A.D., 2014. Net carbon 
uptake has increased through warming-induced changes in temperate forest phenology. Nat. Clim. Chang., 1-7, https:// doi.org/10.1038/NCLIMATE2253

Klosterman S.T., Hufkens K., Gray J.M., Melaas E., Sonnentag O., Lavine I., Mitchell L., Norman R., Friedl M.A., and Richardson A.D., 2014. Evaluating remote sensing of deciduous forest phenology at multiple spatial scales using PhenoCam imagery. Biogeosciences Discuss, 11, 2305-2342, https://doi.org/10.5194/bgd-112305-2014

Kosmala M., Crall A., Cheng R., Hufkens K., Henderson S., and Richardson A., 2016. Season Spotter: Using Citizen Science to Validate and Scale Plant Phenology from NearSurface Remote Sensing. Remote Sensing, 8, 726.

Leith H., 1974. Phenology and seasonality modelling. Springer, Heidelberg.

Liang L., Schwartz M.D., and Fei S., 2011. Validating satellite phenology through intensive ground observation and landscape scaling in a mixed seasonal forest. Remote Sens. Environ., 115, 143-157, https://doi.org/10.1016/j.rse. 2010.08.013

Liu Y., Hill M.J., Zhang X., Wang Z., Richardson A.D., Hufkens K., Filippa G., Baldocchi D.D., Ma S., Verfaillie J., and Schaaf C.B., 2017. Using data from Landsat, MODIS, VIIRS and PhenoCams to monitor the phenology of California oak/grass savanna and open grassland across spatial scales. Agric. For. Meteorol., 237-238, 311-325, https://doi.org/10.1016/j.agrformet.2017.02.026

Melaas E.K., Friedl M.A., and Richardson A.D., 2016. Multiscale modeling of spring phenology across Deciduous Forests in the Eastern United States. Glob. Chang. Biol., 22, 792-805. https://doi.org/10.1111/gcb.13122

Migliavacca M., Galvagno M., Cremonese E., Rossini M., Meroni M., Sonnentag O., Cogliati S., Manca G., Diotri F., Busetto L., Cescatti A., Colombo R., Fava F., Morra di Cella U., Pari E., Siniscalco C., and Richardson A.D., 2011. Using digital repeat photography and eddy covariance data to model grassland phenology and photosynthetic $\mathrm{CO}_{2}$ uptake. Agric. For. Meteorol., 151, 1325-1337, https://doi.org/10.1016/j.agrformet.2011.05.012

Moore C.E., Beringer J., Evans B., Hutley L.B., and Tapper N.J., 2017. Tree-grass phenology information improves light use efficiency modelling of gross primary productivity for an Australian tropical savanna. Biogeosci., 14, 111-129, https://doi.org/10.5194/bg-14-111-2017.

Morrison L.W. and Young C.C., 2016. Observer error in sampling a rare plant population. Plant Ecol. Divers., 9, 289-297, https://doi.org/10.1080/17550874.2016.1220989

Mizunuma T., Mencuccini M., Wingate L., Ogée J., Nichol C., and Grace J., 2014. Sensitivity of colour indices for discriminating leaf colours from digital photographs. Methods in Ecology and Evolution, 5, 1078-1085.

Nagai S., Akitsu T., Saitoh T.M. et al., 2018. 8 million phenological and sky images from 29 ecosystems from the Arctic to the tropics: the Phenological Eyes Network. Ecological Research, 33, 1-2.

Nagai S., Maeda T., Gamo M., Muraoka H., Suzuki R., and Nasahara K.N., 2011. Using digital camera images to detect canopy condition of deciduous broad-leaved trees. Plant Ecol. Divers., 4, 79-89, https://doi.org/10.1080/17550 874.2011.579188
Nasahara K.N. and Nagai S., 2015. Review: Development of an in situ observation network for terrestrial ecological remote sensing: the Phenological Eyes Network (PEN). Ecol. Res., 30, 211-223, https://doi.org/10.1007/s11284-014-1239-x

Petach A.R., Toomey M., Aubrecht D.M., and Richardson A.D., 2014. Monitoring vegetation phenology using an infrared-enabled security camera. Agric. For. Meteorol., 195-196, 143-151, https://doi.org/10.1016/j.agrformet. 2014.05.008

Piao S., Ciais P., Friedlingstein P., Peylin P., Reichstein M., Luyssaert S., Margolis H., Fang J., Barr A., Chen A., Grelle A., Hollinger D.Y., Laurila T., Lindroth A., Richardson A.D., and Vesala T., 2008. Net carbon dioxide losses of northern ecosystems in response to autumn warming. Nature, 451, 49-52, https://doi.org/10.1038/nature06444

Richardson A.D., Anderson R.S., AltafArain M., Barr A.G., Bohrer G., Chen G., Chen J.M., Ciais P., Davis K.J., Desai A.R., Dietze M.C., Dragoni D., Maayar M. El, Garrity S., Gough C.M., Grant R., Hollinger D.Y., Margolis H.A., McCaughey H., Migliavacca M., Monson R.K., William Munger J., Poulter B., Raczka B.M., Ricciuto D.M., Sahoo A.K., Schaefer K., Tian H., Vargas R., Verbeeck H., Xiao J., and Xue Y., 2011. Terrestrial biosphere models need better representation of vegetation phenology: Results from the North American Carbon Program. Glob. Chang. Biol., n/a-n/a. https://doi.org/10.1111/j.1365-2486.2011.02562.x

Richardson A.D., Black T.A., Ciais P., Delbart N., Friedl M.A., Gobron N., Hollinger D.Y., Kutsch W.L., Longdoz B., Luyssaert S., Migliavacca M., Montagnani L., Munger J.W., Moors E., Piao S., Rebmann C., Reichstein M., Saigusa N., Tomelleri E., Vargas R., and Varlagin A., 2010. Influence of spring and autumn phenological transitions on forest ecosystem productivity. Philos. Trans. R. Soc. Lond. B. Biol. Sci., 365, 3227-46. https://doi. org/10.1098/rstb.2010.0102

Richardson A.D., Braswell B.H., Hollinger D.Y., Jenkins J.P., and Ollinger S.V, 2009. Near-surface remote sensing of spatial and temporal variation in canopy phenology. Ecol. Appl., 19, 1417-28.

Richardson A.D., Hufkens K., Milliman T., Aubrecht D.M., Chen M., Gray J.M., Johnston M.R., Keenan T.F., Klosterman S.T., Kosmala M., Melaas E.K., Friedl M.A., and Frolking S., 2018a. Tracking vegetation phenology across diverse North American biomes using PhenoCam imagery. Sci. Data.

Richardson A.D., Hufkens K., Milliman T., and Frolking S., 2018b. Intercomparison of phenological transition dates derived from the PhenoCam Dataset V1.0 and MODIS satellite remote sensing. Sci. Rep.

Richardson A.D., Keenan T.F., Migliavacea M., Ryu Y., Sonnentag O., and Toomey M., 2013. Climate change, phenology, and phenological control of vegetation feedbacks to the climate system. Agric. For. Meteorol., 169, 156-173, https://doi.org/10.1016/j.agrformet.2012.09.012

Robroek B.J.M., Heijboer A., Jassey V.E.J., Hefting M.M., Rouwenhorst T.G., Buttler A., and Bragazza L., 2013. Snow cover manipulation effects on microbial community structure and soil chemistry in a mountain bog. Plant Soil, 369, 151-164, https://doi.org/10.1007/s11104-012-1547-2 
Rosenzweig C., Casassa G., Karoly Imeson A., Liu C., Menzel A., Rawlins S., Root T.L., Seguin B., and Tryjanowski P., 2007. Climate change 2007 : impacts, adaptation and vulnerability: Working Group II contribution to the Fourth Assessment Report of the IPCC Intergovernmental Panel on Climate Change (Eds Parry M.L., Canziani O.F., Palutikof J.P., van der Linden P.J., Hanson C.E.), https://doi.org/10.2134/ jeq2008.0015br

SanClements M. and Roberti J., 2016. Neon Sensor Command Control And Configuration (C3) Document: Phenology Camera / Snow Depth Camera.

Snyder K.A., Wehan B.L., Filippa G., Huntington J.L., Stringham T.K., and Snyder D.K., 2016. Extracting plant phenology metrics in a great basin watershed: Methods and considerations for quantifying phenophases in a cold desert. Sensors (Switzerland), 16, https://doi.org/10.3390/s16111948

Sonnentag O., Hufkens K., Teshera-Sterne C., Young A.M., Friedl M., Braswell B.H., Milliman T., O'Keefe J., and Richardson A.D., 2012. Digital repeat photography for phenological research in forest ecosystems. Agric. For. Meteorol., 152, 159-177, https://doi.org/10.1016/j.agrformet. 2011.09.009

Sus O., Williams M., Bernhofer C., Béziat P., Buchmann N., Ceschia E., Doherty R., Eugster W., Grünwald T., Kutsch W., Smith P., and Wattenbach M., 2010. A linked carbon cycle and crop developmental model: Description and evaluation against measurements of carbon fluxes and carbon stocks at several European agricultural sites. Agric. Ecosyst. Environ., 139, 402-418, https://doi.org/https://doi. org/10.1016/j.agee.2010.06.012

Toomey M., Friedl M.A., Frolking S., Hufkens K., Klosterman S., Sonnentag O., Baldocchi D.D., Bernacchi C.J., Biraud S.C., and Richardson A.D., 2015. Greenness indices from digital cameras predict the timing and seasonal dynamics of canopy-scale photosynthesis. Ecol. Appl., 25, 99-115.
Vrieling A., Meroni M., Darvishzadeh R., Skidmore A.K., Wang T., Zurita-Milla R., Oosterbeek K., O'Connor B., and Paganini M., 2018. Vegetation phenology from Sentinel-2 and field cameras for a Dutch barrier island. Remote Sens. Environ., 1-13, https://doi.org/10.1016/j. rse.2018.03.014

Wingate L., Ogeé J., Cremonese E., Filippa G., Mizunuma T., Migliavacca M., Moisy C., Wilkinson M., Moureaux C., Wohlfahrt G., Hammerle A., Hörtnagl L., Gimeno C., Porcar-Castell A., Galvagno M., Nakaji T., Morison J., Kolle O., Knohl A., Kutsch W., Kolari P., Nikinmaa E., Ibrom A., Gielen B., Eugster W., Balzarolo M., Papale D., Klumpp K., Köstner B., Grünwald T., Joffre R., Ourcival J.M., Hellstrom M., Lindroth A., George C., Longdoz B., Genty B., Levula J., Heinesch B., Sprintsin M., Yakir D., Manise T., Guyon D., Ahrends H., Plaza-Aguilar A., Guan J.H., and Grace J., 2015. Interpreting canopy development and physiology using a European phenology camera network at flux sites. Biogeosciences, 12, 5995-6015, https://doi.org/10.5194/ bg-12-5995-2015

Woebbecke D., Meyer G., Von Bargen K., and Mortensen D., 1995. Color indices for weed identification under various soil, residue, and lighting conditions. Trans. ASAE, 38, 259-269.

Wohlfahrt G., Cremonese E., Hammerle A., Hörtnagl L., Galvagno M., Gianelle D., Marcolla B., and di Cella U.M., 2013. Trade-offs between global warming and day length on the start of the carbon uptake period in seasonally cold ecosystems. Geophys. Res. Lett., 40, n/a-n/a. https://doi.org/10.1002/2013GL058182

Xie Y., Wang X., and Silander J.A., 2015. Deciduous forest responses to temperature, precipitation, and drought imply complex climate change impacts. Proc. Natl. Acad. Sci., 112, 13585-13590, https://doi.org/10.1073/pnas.1509991112 